Béatrice Heurtault, Nathalie Reix, Nicolas Meyer, Françoise Gasser, Marie-Josée Wendling, Charline Ratomponirina, Nathalie Jeandidier, Rémy Sapin and Arnaud Agin*

\title{
Extensive study of human insulin immunoassays: promises and pitfalls for insulin analogue detection and quantification
}

\begin{abstract}
Background: Over the last few decades, new synthetic insulin analogues have been developed. Their measurement is of prime importance in the investigation of hypoglycaemia, but their quantification is hampered by variable cross-reactivity with many insulin assays. For clinical analysis, it has now become essential to know the potential cross-reactivity of analogues of interest.

Methods: In this work, we performed an extensive study of insulin analogue cross-reactivity using numerous human insulin immunoassays. We investigated the crossreactivity of five analogues (lispro, aspart, glulisine, glargine, detemir) and two glargine metabolites (M1 and M2) with 16 commercial human insulin immunoassays as a function of concentration.

Results: The cross-reactivity values for insulin analogues or glargine metabolites ranged from $0 \%$ to $264 \%$. Four assays were more specific to human insulin, resulting in negligible cross-reactivity with the analogues. However, none of the 16 assays was completely free of cross-reactivity with analogues or metabolites. The results show that analogue cross-reactivity, which varies to a large degree, is far from negligible, and should not be overlooked in clinical investigations.

Conclusions: This study has established the cross-reactivity of five insulin analogues and two glargine metabolites using 16 immunoassays to facilitate the choice of the immunoassay(s) and to provide sensitive and specific analyses in clinical routine or investigation.
\end{abstract}

Keywords: cross-reactivity; human insulin; immunoassays; insulin analogues.

*Corresponding author: Arnaud Agin, Laboratoire d'Hormonologie, Hôpitaux Universitaires de Strasbourg, 1 place de l'Hôpital, 67091 Strasbourg Cedex, France, Fax: +33 369551885, E-mail: agin@unistra.fr; and ICube UMR7357 Université de Strasbourg/CNRS, Fédération de Médecine Translationnelle de Strasbourg (FMTS), Strasbourg, France
Béatrice Heurtault: Laboratoire d'Hormonologie, Hôpitaux Universitaires de Strasbourg, Strasbourg, France; and Equipe de Biovectorologie, Laboratoire de Conception et Application de Molécules Bioactives, UMR 7199 CNRS/Université de Strasbourg, Faculté de Pharmacie, Illkirch Graffenstaden, France

Nathalie Reix: Laboratoire d'Hormonologie, Hôpitaux Universitaires de Strasbourg, Strasbourg, France; and ICube UMR7357 Université de Strasbourg/CNRS, Fédération de Médecine Translationnelle de Strasbourg (FMTS), Strasbourg, France

Nicolas Meyer: Service de Santé Publique, Hôpitaux Universitaires de Strasbourg, Strasbourg, France

Françoise Gasser and Rémy Sapin: Laboratoire d'Hormonologie, Hôpitaux Universitaires de Strasbourg, Strasbourg, France Marie-Josée Wendling: Laboratoire de Virologie, Hôpitaux Universitaires de Strasbourg, Strasbourg, France

Charline Ratomponirina: Laboratoire de Biochimie et de Biologie Moléculaire, Hôpitaux Universitaires de Strasbourg, Strasbourg, France

Nathalie Jeandidier: Service d'endocrinologie et des maladies de la nutrition, Pôle NUDE, Hôpitaux Universitaires de Strasbourg, Université de Strasbourg, Strasbourg, France

\section{Introduction}

Measurement of insulin concentration is useful to investigate hypoglycaemia, $\beta$-cell function, insulin resistance, insulinoma, and to determine the pathogenesis of type 1 and 2 diabetes. Even if, owing to analytical pitfalls [1, 2], commercially available human insulin assays are still awaiting standardisation, they are currently used in clinical investigation [2-5]. Insulin is synthesised in the $\beta$-cells of the islets of Langerhans as a proinsulin precursor, which is processed to form insulin and C-peptide. Both are secreted in equimolar amounts into the portal circulation. Thus, recombinant insulin administration can be suspected when insulin and C-peptide levels are discordant: a suppressed or undetectable C-peptide value associated with a normal-to-elevated insulin value is in favour of synthetic insulin administration taking into account their distinct half-life. When pharmaceutical recombinant insulin, with a sequence identical to that of human insulin, is 
administered, human insulin assays are usually coupled with C-peptide measurements to distinguish exogenous synthetic insulin injections from physiological insulin.

Owing to the limiting pharmacokinetic and pharmacodynamic features of the recombinant human insulin sequence, rapid- and/or long-acting analogues have been used since 1996 [6]. These new synthetic insulin analogues have complicated the detection of synthetic insulin. Thevis et al. have largely described mass spectrometry-based methods for insulin analogue assessment [7-11]. However, these methods are highly technically demanding. They have been described for anti-doping test purposes and are not widespread. Furthermore, as preliminary immunoextraction is required prior to chromatographic and mass spectrometric analysis, assay performances are limited to detection without quantification.

Human insulin immunoassays are easy to perform, but clinicians and clinical chemists must be aware that possible cross-reactivity has already been highlighted between endogenous or exogenous standard insulin and analogues in sera assays [12-14]. Failing that, misdiagnosis can occur as described in the observation by Krull et al. [15]. In that case, hypoglycaemia was initially associated to non-measurable plasma insulin levels (Elecsys, Roche Diagnostics), which could be attributed to deficiencies in counter-regulatory hormones such as cortisol or growth hormone, severe hepatic or renal failure or large non-islet tumours producing IGF-2. However, a second insulin assay performed with Advia Centaur ${ }^{\circledR}$ (Siemens), yielded high "insulin" levels due to significant cross-reactivity with insulin glargine and lispro. A secret insulin administration, responsible for the factitious hypoglycaemia, was thus detected [15]. In another case report, despite a serum insulin concentration within the reference range, hypoglycaemia was observed. The surreptitious association of human insulin with glargine and insulin aspart escaped detection owing to low cross-reactivity between the analogues and human insulin in the insulin assays [16]. Lack of control of cross-reactivity of insulin analogues leads to misdiagnosis with clearly established clinical impact. As a consequence, different studies focused on the determination of the cross-reactivity of various analogues using one particular insulin assay [14, 17-22]. Those works showed, for example, that the Architect insulin assay (Abbott Laboratories) had a low cross-reactivity to the insulin analogue aspart, whereas it detected lispro and glargine, in concentrations as high as the theoretical concentrations [12]. More recently, Vieira et al. (2007) showed cross-reactivity between insulin glargine and regular human insulin in an immunofluorimetric assay provided by PerkinElmer [14]. However, from a practical point of view, it is essential to define the technique (or combination of techniques) that will highlight the presence or absence of insulin analogues. This involves extending such studies to a wide range of immunoassays, an undertaking initiated by Owen in 2004 [13].

To address this situation, in the present study, we set about an extensive evaluation of the cross-reactivity of rapid- (lispro, glulisine, aspart) and long-acting (detemir, glargine and its two metabolites: M1, M2) analogues with numerous and frequently used commercial assays. A comparison of 16 human insulin immunoassays has been performed for both insulin analogues and glargine metabolites. This study includes glulisine, the latest addition to rapid analogues, whose cross-reactivity has not been studied at all, and the glargine metabolites whose cross-reactivity has only been assessed with very few assays [14, 15]. Four insulin analogue concentrations were analysed ranging from 10 to $200 \mathrm{mU} / \mathrm{L}$ in PBS-1\% BSA (or 60-1200 pmol/L for glargine metabolites) to determine their cross-reactivity with human insulin as a function of concentration.

\section{Materials and methods}

\section{Insulin, insulin analogues and metabolites}

The structure and activity of insulin analogues are presented in the Supplemental Data Table S1, which accompanies the article at http://www.degruyter.com/view/j/cclm.2014.52.issue-3/issue-files/ cclm.2014.52.issue-3.xml. Human recombinant insulin (Actrapid 100 $\mathrm{IU} / \mathrm{mL}$ ), aspart (Novorapid $100 \mathrm{U} / \mathrm{mL}$ ) and detemir (Levemir $100 \mathrm{U} / \mathrm{mL}$ ) were obtained from Novo Nordisk (Puteaux, France), lispro (Humalog 100 U/mL) from Lilly (Suresnes, France), glargine (Lantus 100 U/mL) and glulisine (Apidra $100 \mathrm{U} / \mathrm{mL}$ ) from Sanofi-Aventis (Paris, France). M1 and M2 (glargine metabolites) were kind gifts from Sanofi-Aventis (Professor J. Sandow, Frankfurt, Germany).

\section{Insulin assays}

The characteristics of the commercially available insulin assays are described in the Supplemental Data, Table S2. Assays were kind gifts of Abbott Diagnostics (Insulin Architect; Rungis, France), Beckman Coulter France (Ultrasensitive Insulin Access and Insulin IRMA kit; Roissy, France), DIAsource Europe S.A. (INS-EASIA and INS-IRMA; Nivelles, Belgium), CIS Bio (Insulin-CT and Bi-insulin IRMA; Gifsur-Yvette, France), DiaSorin (Liaison Insulin, INSI CTK-IRMA and INSIK-5; Antony, France), PerkinElmer (Wallac AutoDELFIA insulin; Villebon-sur-Yvette, France), Roche Diagnostics (Insulin Elecsys; Meylan, France), Siemens (Advia Centaur Insulin - IRI, Coat-A-Count Insulin; Puteaux, France), Tosoh (ST-AIA-PACK IRI, Lyon, France). Human insulin-specific RIA kit was purchased (Millipore, Saint Charles, USA). 


\section{Samples}

Insulin analogues contained in pen treatment units, and glargine metabolites were successively diluted in PBS-1\% BSA to final concentrations of 10, 30, 100, and $200 \mathrm{mU} / \mathrm{L}$, and 60, 180, 600 and 1200 pmol/L, respectively, using a semi-automated diluter (Microlab 500, Hamilton, Reno, USA). The dilution steps of the stock solutions were validated by using a ${ }^{125}$ I-labelled solution. Each dilution point was prepared three times.

In order to study the influence of insulin analogues and glargine metabolites on human insulin measurement they were mixed at a final concentration of $100 \mathrm{mU} / \mathrm{L}$ and $600 \mathrm{pmol} / \mathrm{L}$, respectively, with recombinant insulin (final concentration of $100 \mathrm{mIU} / \mathrm{L}$ ) in PBS$1 \%$ BSA (data not shown).

\section{Matrix}

As glargin is metabolised by enzymes such as carboxypeptidases present in serum or plasma, the former were replaced by proteinsupplemented PBS for the assays. We consequently tested different BSA concentrations ranging from $1 \%$ to $8 \%$ in PBS, in absence of insulin with 17 assays (data not shown). The Immulite assay was initially part of the study, but the results were not included in our paper, because the matrix alone (PBS-BSA without analogue or insulin) surprisingly displayed results between $19 \mathrm{mIU} / \mathrm{L}$ and $41 \mathrm{mIU} / \mathrm{L}$ for BSA concentrations between $1 \%$ and $8 \%$. That matrix was clearly not suitable to study Immulite. We did not observe such inconsistencies with the other assays whatever the BSA concentration and PBS-BSA $1 \%$ has been retained.

\section{Statistics}

In order to test the validity of the different assays, linearity tests were performed according to the method previously described [23]. When significant, the test on departure from linearity leads to the rejection of the linearity assumption. A p-value less than 0.05 was considered as significant and indicated lack of linearity throughout the range of different concentrations. Computations were run with R 2.14".

\section{Results}

Table 1 represents the cross-reactivity values obtained, for analogues and metabolites, as a function of the molecules assessed and their concentrations, with 16 immunoassays. The percentage of cross-reactivity was calculated from the ratio of the measured and nominal concentrations. The details of the methods used by the assays (type, principle, category, antibodies...) are described in the Supplemental Data, Table S2. These assays cover the most frequently used assays in the field and the various methods: automated or manual as well as two-site immunometric or competition assays. As a pre-requisite, we show that most commercial insulin assays (10/16) quantitatively detected human recombinant insulin $\left(\right.$ Actrapid $\left.^{\circledR}\right)$ whatever the concentrations between 10 and $200 \mathrm{mIU} / \mathrm{L}$ (Supplemental Data, Table S3). The source of discrepancies in results among commercial methods of insulin immunoassays is likely multifactorial and not explainable by a single analytical performance characteristic [4]. Matrix effects in combination with the fact that insulin assays are still calling for standardisation can explain this result [4, 24].

\section{Insulin analogues}

We studied three short-acting and two long-acting insulin analogues using the same 16 commercial assays (Table 1 and Supplemental Data, Table S1). The cross-reactivity values were comprised between $0 \%$ and $264 \%$ as a function of the analogues. A similar scale was also observed for a single analogue, i.e., detemir, yielding cross-reactivity values between $0 \%$ and $264 \%$ as a function of the assays used. Furthermore, let us note that four assays (Elecsys Roche, Diasorin Liaison, Ins-IRMA Beckman and Wallac AutoDELFIA PerkinElmer) showed a high specificity to human insulin, with no or little cross-reactivity whatever the analogue studied.

\section{Glargine metabolites}

Insulin glargine is a long-acting human insulin analogue. Following subcutaneous administration insulin glargine precipitates. Proteolytic degradation results in two main active metabolites: M1 and M2, formed by the sequential removal of the two arginines from the carboxy-terminus of the B-chain and additional deamination of threonine in position B30 $[25,26]$. Their similarity with the human insulin structure led to check their cross-reactivity. As with analogues, the performance of the various commercial assays was not uniform with respect to cross-reactivity with both glargine metabolites. Cross-reactivity was close to $100 \%$ in five immunoassays, and at least two others displayed cross-reactivity values $<5 \%$. In general, a given assay yielded similar cross-reactivity values for the two metabolites, except for Elecsys, which presented crossreactivity for M1 around 22\% but none for M2.

\section{Influence of concentration}

Table 1 details the effect of analogue concentration (between 10 and $200 \mathrm{mU} / \mathrm{L}$ ) and metabolite concentration 
Table 1 Cross-reactivities (\%) of insulin analogues and two metabolites of glargine.

\begin{tabular}{|c|c|c|c|c|c|c|c|c|}
\hline \multirow{3}{*}{$\begin{array}{l}\text { Concentration, } \\
\mathrm{mU} / \mathrm{L}\end{array}$} & \multicolumn{5}{|c|}{ Analogues } & \multicolumn{3}{|c|}{ Glargine metabolites } \\
\hline & \multicolumn{3}{|c|}{ Short action } & \multicolumn{2}{|c|}{ Long action } & \multirow[t]{2}{*}{ Concentration, pmol/L } & \multirow[t]{2}{*}{ M1 } & \multirow[t]{2}{*}{ M2 } \\
\hline & Lispro & Aspart & Glulisine & Glargine & Detemir & & & \\
\hline \multicolumn{9}{|c|}{ Access (Beckman) } \\
\hline 10 & 87 & 92 & 0.3 & 110 & 9 & 60 & 130 & 130 \\
\hline 30 & 89 & 91 & 0.9 & 106 & 12 & 180 & 120 & 120 \\
\hline 100 & 91 & 93 & 4.9 & 100 & 21 & 600 & 109 & 109 \\
\hline 200 & 93 & 93 & 10.7 & 95 & 26 & 1200 & 104 & 104 \\
\hline \multicolumn{9}{|c|}{ Advia Centaur IRI (Siemens) } \\
\hline 10 & 99 & 143 & 8 & 137 & 32 & 60 & 120 & 139 \\
\hline 30 & 97 & 138 & 3 & 135 & 28 & 180 & 117 & 141 \\
\hline 100 & 101 & 148 & 2 & 154 & 27 & 600 & 129 & 138 \\
\hline 200 & 115 & $>150$ & 2 & $>144$ & 27 & 1200 & 128 & 143 \\
\hline \multicolumn{9}{|c|}{ Architect (Abbott Laboratories) } \\
\hline 10 & 85 & 61 & $<10$ & 110 & 52 & 60 & 123 & 118 \\
\hline 30 & 83 & 62 & 4.9 & 108 & 60 & 180 & 116 & 113 \\
\hline 100 & 87 & 67 & 7 & 108 & 87 & 600 & 114 & 109 \\
\hline 200 & 86 & 71 & 8.9 & 106 & 98 & 1200 & 109 & 104 \\
\hline \multicolumn{9}{|c|}{ Wallac AutoDELFIA Insulin (PerkinElmer) } \\
\hline 10 & $<5$ & $<7.3$ & $<5$ & $<5$ & $<5$ & 60 & $<5$ & $<5$ \\
\hline 30 & $<1.7$ & $<1.7$ & $<1.7$ & 5 & $<1.7$ & 180 & 4 & $<1.7$ \\
\hline 100 & $<0.5$ & $<0.5$ & $<0.5$ & 12 & $<0.5$ & 600 & 10 & $<0.5$ \\
\hline 200 & $<0.25$ & $<0.25$ & $<0.25$ & 18 & $<0.25$ & 1200 & 16 & $<0.25$ \\
\hline \multicolumn{9}{|c|}{ Bi-insulin IRMA (CIS Bio) } \\
\hline 10 & 97 & 95 & $<2$ & 115 & 230 & 60 & 116 & 114 \\
\hline 30 & 107 & 104 & $<1$ & 126 & 239 & 180 & 130 & 126 \\
\hline 100 & 103 & 101 & 2 & 117 & 221 & 600 & 119 & 116 \\
\hline 200 & 98 & 101 & 3 & 115 & 212 & 1200 & 113 & 112 \\
\hline \multicolumn{9}{|c|}{ Cobas/Elecsys (Roche Diagnostics) } \\
\hline 10 & $<2$ & $<2$ & $<2$ & $<2$ & $<2$ & 60 & 23 & $<2$ \\
\hline 30 & $<0.7$ & $<0.7$ & $<0.7$ & $<0.7$ & $<0.7$ & 180 & 22 & $<0.7$ \\
\hline 100 & $<0.2$ & $<0.2$ & $<0.2$ & $<0.2$ & $<0.2$ & 600 & 21 & $<0.25$ \\
\hline 200 & $<0.1$ & $<0.1$ & $<0.1$ & $<0.1$ & 0.1 & 1200 & 21 & 0.1 \\
\hline \multicolumn{9}{|c|}{ Coat-A-Count (Siemens) } \\
\hline 10 & $<50$ & $<50$ & $<50$ & $<50$ & $<50$ & 60 & $<50$ & $<50$ \\
\hline 30 & 48 & 42 & $<17$ & $<17$ & $<17$ & 180 & $<17$ & $<17$ \\
\hline 100 & 54 & 50 & 7 & 8 & 7 & 600 & 6 & 7 \\
\hline 200 & 48 & 45 & 10 & 7 & 7 & 1200 & 6 & 6 \\
\hline \multicolumn{9}{|c|}{ Human insulin Specific RIA (Millipore) } \\
\hline 10 & 114 & 85 & 64 & 155 & 44 & 60 & 104 & 111 \\
\hline 30 & 96 & 68 & 54 & 164 & 37 & 180 & 100 & 94 \\
\hline 100 & 81 & 55 & 48 & 159 & 33 & 600 & 101 & 82 \\
\hline 200 & 73 & 51 & 47 & $>94$ & 30 & 1200 & $>77$ & 72 \\
\hline \multicolumn{9}{|c|}{ Ins-EASIA (DIAsource) } \\
\hline 10 & 76 & 74 & 80 & 86 & 67 & 60 & 123 & 92 \\
\hline 30 & 27 & 33 & 26 & 32 & 17 & 180 & 38 & 25 \\
\hline 100 & 8 & 7 & 8 & 20 & 7 & 600 & 16 & 10 \\
\hline 200 & 6 & 4 & 6 & 19 & 5 & 1200 & 13 & 6 \\
\hline Ins-IRMA (Immu & Beckma & & & & & & & \\
\hline 10 & $<5$ & $<5$ & $<5$ & $<5$ & $<5.6$ & 60 & $<5$ & $<5$ \\
\hline 30 & $<1.7$ & $<1.7$ & $<1.7$ & 3 & $<1.9$ & 180 & $<2.6$ & $<2.30$ \\
\hline 100 & $<0.5$ & $<0.5$ & $<0.5$ & 7 & $<0.5$ & 600 & 4 & $<0.7$ \\
\hline 200 & $<0.25$ & $<0.28$ & $<0.25$ & 13 & $<0.26$ & 1200 & 8 & 0 \\
\hline INSI-CTK IRMA ( & & & & & & & & \\
\hline 10 & 97 & 109 & $<4$ & 22 & 105 & 60 & $<35$ & $<17$ \\
\hline 30 & 92 & 105 & $<1$ & 12 & 115 & 180 & 23 & 24 \\
\hline
\end{tabular}


(Table 1 Continued)

\begin{tabular}{|c|c|c|c|c|c|c|c|c|}
\hline \multirow{3}{*}{$\begin{array}{l}\text { Concentration, } \\
\mathrm{mU} / \mathrm{L}\end{array}$} & \multicolumn{5}{|c|}{ Analogues } & \multicolumn{3}{|c|}{ Glargine metabolites } \\
\hline & \multicolumn{3}{|c|}{ Short action } & \multicolumn{2}{|c|}{ Long action } & \multirow[t]{2}{*}{ Concentration, pmol/L } & \multirow[t]{2}{*}{ M1 } & \multirow[t]{2}{*}{ M2 } \\
\hline & Lispro & Aspart & Glulisine & Glargine & Detemir & & & \\
\hline 100 & 99 & 106 & $<0.9$ & 16 & 125 & 600 & 36 & 29 \\
\hline 200 & $>93$ & $>100$ & $<0.15$ & 16 & $>100$ & 1200 & 39 & 42 \\
\hline \multicolumn{9}{|c|}{ INSIK-5 (DiaSorin) } \\
\hline 10 & 49 & 64 & 42 & $<55$ & 71 & 60 & 46 & 44 \\
\hline 30 & 62 & 65 & 37 & 44 & 52 & 180 & 57 & 49 \\
\hline 100 & 57 & 63 & 22 & 29 & 28 & 600 & 49 & 40 \\
\hline 200 & 49 & 55 & 15 & 23 & 18 & 1200 & 38 & 34 \\
\hline \multicolumn{9}{|c|}{ Insulin-CT (Cis Bio) } \\
\hline 10 & 89 & 80 & 95 & 59 & 172 & 60 & 105 & 78 \\
\hline 30 & 95 & 104 & 90 & 76 & 220 & 180 & 99 & 101 \\
\hline 100 & 103 & 109 & 81 & 85 & 264 & 600 & 95 & 103 \\
\hline 200 & 110 & 118 & 71 & 83 & $>155$ & 1200 & 90 & 94 \\
\hline \multicolumn{9}{|c|}{ INS-IRMA (DIAsource) } \\
\hline 10 & 66 & 64 & 65 & 79 & 62 & 60 & 70 & 65 \\
\hline 30 & 22 & 22 & 23 & 47 & 22 & 180 & 35 & 23 \\
\hline 100 & 7 & 7 & 7 & 48 & 6 & 600 & 30 & 9 \\
\hline 200 & 3 & 3 & 3 & 51 & 3 & 1200 & 32 & 7 \\
\hline \multicolumn{9}{|c|}{ Liaison (DiaSorin) } \\
\hline 10 & $<2$ & $<2$ & $<2$ & $<6$ & $<2$ & 60 & $<2$ & $<2$ \\
\hline 30 & $<0.7$ & $<0.7$ & $<0.7$ & 6 & $<0.7$ & 180 & 7 & $<0.7$ \\
\hline 100 & $<0.2$ & $<0.2$ & $<0.2$ & 18 & $<0.2$ & 600 & 17 & $<1$ \\
\hline 200 & $<0.1$ & $<0.1$ & $<0.1$ & 29 & $<0.1$ & 1200 & 27 & $<0.8$ \\
\hline \multicolumn{9}{|c|}{ ST AIA-PACK IRI (Tosoh) } \\
\hline 10 & 106 & 122 & 63 & 16 & 58 & 60 & 43 & 63 \\
\hline 30 & 109 & 124 & 67 & 20 & 60 & 180 & 50 & 70 \\
\hline 100 & 113 & 126 & 78 & 36 & 72 & 600 & 74 & 84 \\
\hline 200 & 112 & 121 & 79 & 50 & 76 & 1200 & 84 & 98 \\
\hline
\end{tabular}

Absence of statistical analysis owing to values under the detection threshold of the method: italic font type.

(between 60 and $1200 \mathrm{pmol} / \mathrm{L}$ ) on cross-reactivity values. Cross-reactivity increased or more frequently decreased as a function of concentration. Indeed the DIAsource INS-IRMA assay could detect analogues with around 65\% cross-reactivity when their concentrations were around $10 \mathrm{mU} / \mathrm{L}$, but cross-reactivity gradually decreased as a function of concentration, down to $3 \%$ at $200 \mathrm{mU} / \mathrm{L}$. Statistical analysis allowed to highlight the cross-reactivity results that varied linearly as a function of concentration (Supplemental Data, Figure S1). Cross-reactivity was linear in 58\% of the immunoassays (65/112), and some immunoassays yielded predominantly linear results whatever the analogue, i.e., Ins-EASIA, DIAsource and Insulin-CT, Cis Bio. The linearity could not be correlated with the insulin analogue or the immunoassay methods used. Analogue concentration appears to be an important parameter to take into account in the choice of the insulin assay to be used. In some cases, statistical analysis of the results obtained with some analogues was not possible when those were under the method detection threshold (italic font in Table 1) (26/112). However, despite of the lack of statistical analysis, one can conclude that these methods are not suitable for the detection of these analogues.

\section{Discussion}

The aim of the current study was to highlight and measure with commonly used immunoassays the possible crossreactivity of various analogues. All the measurements were performed in the presence of albumin to limit the adsorption of analogues to plastic-ware occurring in the absence of protein, thus diminishing the amount available for detection by the assays [27].

In our work, the study of the analogues showed that four assays were specific to human insulin, resulting in negligible cross-reactivity with the analogues while yielding values $>90 \%$ for human insulin. Cross-reactivity is a function of the binding of the antibodies employed in the assay. Human insulin has antigenic determinants differing 
from the antigenic sites of insulin analogues. One of them is comprised between the positions $27-30$ of the B-chain [28] and the other concerns the residues $8-10$ of the A-chain $[29,30]$. Considering the structure of the studied analogues (Supplemental Data, Table S1), the results suggest that at least these four assays are based on the use of antibodies recognising the $\mathrm{C}$-terminal part of the B-chain, which is altered within the sequence of the analogues studied, hence the lack of or very low cross-reactivity. These results confirm and extend the scope of the lack of cross-reactivity reported in 2001 using the Elecsys method applied to lispro measurements [21]. In the same way, the difference in cross-reactivity between the glargine metabolites (M1 and M2) using the Elecsys assay can be explained by the structure of M1, with a conserved B-chain maintaining recognition by antibodies directed against the C-terminal part of the B-chain and probably used in the Elecsys method. M2 is not recognised owing to the alteration of the $\mathrm{C}$-terminal part of the B-chain. It is of prime importance to discriminate glargine from its metabolites. Indeed, we henceforth know that after injection, glargine is minimally detectable in blood due to its rapid conversion into M1 and M2 metabolites. A relation between glargine administration and a risk of cancer was assumed partly due to in vitro studies but this relation is challenged [31]. Pierre-Eugène et al. showed that pro-mitogenic properties of glargine in cultured cells should be abrogated in vivo by its rapid conversion into metabolites [32]. Recent studies on type 1 and 2 diabetic subjects showed that the long-acting metabolic effects are related to the main metabolite M1 $[33,34]$ reinforcing the importance of its specific detection and quantification.

The effect of the primary ligand (human insulin in our study) on the degree of observed cross-reactivity has been previously described. According to Miller and Valdes, depending on the assay, human insulin may moderately decrease or increase cross-reactivity with insulin analogues $[35,36]$. In our work, the simultaneous presence of the primary ligand (human insulin) and of the cross-reactant have miscellaneous effects depending on the assay and on the analogue assessed (data not shown).

The various immunoassays used were either two-site specific immunometric or competitive assays (Supplemental Data, Table S2). We can note in Table 1 that competitive assays (Coat-A-Count, Siemens; Human Insulin Specific RIA, Millipore; INSIK-5, DiaSorin; Insulin-CT, Cis Bio) were able to detect all the analogues and metabolites resulting in non-negligible cross-reactivity. As a consequence, these four methods do not appear in the last column of Table 2 , which highlights methods without cross-reactivity with any analogue or metabolite. This result is consistent with the fact that the polyclonal antibodies used for competitive assays provide lesser specificity compared to monoclonal antibodies.

In competitive immunoassays using polyclonal antibodies (e.g., Human insulin specific RIA and INSIK-5), the decrease in measured cross-reactivity as the concentration of cross-reactant increases has already been described by Miller and Valdes [35, 36]. In a polyclonal antiserum, multiple antibodies display varying affinities for the primary antigen.

Sets of antibodies with low affinity for the standard antigen may have a high affinity for the cross-reactant. The first small amounts of cross-reactant easily displace bound label from these less specific antibodies. As the cross-reactant saturates the less specific antibodies, additional amounts of cross-reactant are less likely to displace bound label from the more specific antibodies. Owen et al. had previously studied the cross-reactivity of three recombinant insulin analogues (insulin aspart, glargine, insulin lispro) with five commercial insulin immunoassays in the presence of BSA. The large variability in the degree of crossreactivity of those analogues with the five different commercial assays is noteworthy [13]. We have reached the same conclusion, i.e., that of a large variability in cross-reactivity through the extensive study of five insulin analogues and two metabolites using 16 immunoassays. Table 2 summarises the specific assay(s) that can be used ( $>90 \%$ crossreactivity) as well as the commercial assays without any cross-reactivity $(<5 \%)$ for each analogue. It shows that few methods allow the detection of glulisine, but for one with cross-reactivity around 90\% (Insulin-CT, CisBio). For every other analogue, there is at least one available assay able to detect the molecule with high cross-reactivity (90\%-110\%). As a consequence, when secret insulin administration is suspected one of the four human insulin-specific assays should be used in parallel with a second insulin assay presenting significant cross-reactivity with insulin analogues. Krull et al. [15] have shown the benefit of knowing the capacity of individual assays to measure or not insulin analogues. In their work, they evidenced a case of factitious hypoglycaemia by self-administration of lispro and glargine, thanks to the complementary use of both Elecsys ${ }^{\circledR}$ and Advia Centaur ${ }^{\circledR}$ assays and their discordant results [15].

This work shows that insulin immunoassays have various degrees of cross-reactivity with insulin analogues and their metabolites. However, knowing that kit manufacturers may change lots of reagent antibodies (mainly for polyclonal antibodies) [37] sometimes without communicating such changes to laboratory users, we therefore do recommend the use of specific in-house quality controls (i.e., samples with analogue dilutions) to validate new kit lots before assessing insulin analogues. Nevertheless, 
Table 2 Cross-reactivity of five analogues and two glargine metabolites as a function of the commercial assay used.

\begin{tabular}{|c|c|c|}
\hline Name & $\begin{array}{l}>90 \% \text { cross-reactivity } \\
\text { (for each } 4 \text { concentrations) }\end{array}$ & $\begin{array}{l}<5 \% \text { Cross-reactivity } \\
\text { (for each } 4 \text { concentrations) }\end{array}$ \\
\hline Humalog (lispro) & $\begin{array}{l}\text { Access (Beckman)IRMA (CIS Bio) } \\
\text { Insulin-CT (CisBio) } \\
\text { ST AIA-PACK IRI (Tosoh) }\end{array}$ & $\begin{array}{l}\text { Wallac AutoDELFIA (PerkinElmer) } \\
\text { Cobas/Elecsys (Roche Diagnostics) } \\
\text { Ins-IRMA (Beckman) } \\
\text { Liaison (Diasorin) }\end{array}$ \\
\hline Novorapid (aspart) & $\begin{array}{l}\text { Access (Beckman) } \\
\text { Advia Centaur (Siemens) } \\
\text { Bi-insulin IRMA (CIS Bio) } \\
\text { INSI CTK-IRMA (DiaSorin) } \\
\text { Insulin-CT (CisBio) except for } 10 \mathrm{mU} / \mathrm{L} \\
\text { ST AIA-PACK IRI (Tosoh) }\end{array}$ & $\begin{array}{l}\text { Wallac AutoDELFIA (PerkinElmer) } \\
\text { Cobas/Elecsys (Roche Diagnostics) } \\
\text { Ins-IRMA (Beckman) } \\
\text { Liaison (Diasorin) }\end{array}$ \\
\hline Apidra (glulisine) & & $\begin{array}{l}\text { Wallac AutoDELFIA (PerkinElmer) } \\
\text { Bi-insulin IRMA (CIS Bio) } \\
\text { Ins-IRMA (Beckman) } \\
\text { INSI CTK-IRMA (DiaSorin) } \\
\text { Liaison (Diasorin) }\end{array}$ \\
\hline Lantus (glargine) & $\begin{array}{l}\text { Access (Beckman) } \\
\text { Advia Centaur (Siemens) } \\
\text { Architect (Abbott) } \\
\text { Bi-insulin IRMA (CIS Bio) }\end{array}$ & $\begin{array}{l}\text { Cobas/Elecsys (Roche Diagnostics) } \\
\text { Human Insulin Specific RIA (Millipore) } \\
\text { Ins-IRMA (Beckman) except for } 200 \mathrm{mU} / \mathrm{L}\end{array}$ \\
\hline Levemir (detemir) & $\begin{array}{l}\text { Bi-insulin IRMA (CIS Bio) } \\
\text { INSI CTK-IRMA (DiaSorin) } \\
\text { Insulin-CT (CisBio) }\end{array}$ & $\begin{array}{l}\text { Wallac AutoDELFIA (PerkinElmer) } \\
\text { Cobas/Elecsys (Roche Diagnostics) } \\
\text { Ins-IRMA (Beckman) } \\
\text { Liaison (Diasorin) }\end{array}$ \\
\hline M1 & $\begin{array}{l}\text { Access (Beckman) } \\
\text { Advia Centaur (Siemens) } \\
\text { Architect (Abbott laboratories) } \\
\text { Bi-insulin IRMA (CIS Bio) } \\
\text { Insulin-CT (CisBio) }\end{array}$ & $\begin{array}{l}\text { Human Insulin Specific RIA (Millipore) } \\
\text { Ins-IRMA (Beckman) }\end{array}$ \\
\hline M2 & $\begin{array}{l}\text { Access (Beckman) } \\
\text { Advia Centaur (Siemens) } \\
\text { Architect (Abbott laboratories) } \\
\text { Bi-insulin IRMA (CIS Bio) } \\
\text { Insulin-CT (CIS Bio) except for } 60 \mathrm{pmol} / \mathrm{L}\end{array}$ & $\begin{array}{l}\text { Wallac AutoDELFIA (PerkinElmer) } \\
\text { Cobas/Elecsys (Roche Diagnostics) } \\
\text { Ins-IRMA (Beckman) } \\
\text { Liaison (Diasorin) }\end{array}$ \\
\hline
\end{tabular}

this study brings a very useful comparison of immunoassays available to clinicians when they must discriminate between insulin of various origins.

Acknowledgments: The authors thank G. Coumaros and all the hormonology laboratory technicians for their technical assistance on this project as well as Klump and Guth laboratories (Strasbourg, France). We also specifically acknowledge Nathalie Heider for carefully reviewing the manuscript including English revision.

\section{Conflict of interest statement}

Authors' conflict of interest disclosure: The authors stated that there are no conflicts of interest regarding the publication of this article.

Research funding: None declared.

Employment or leadership: None declared.

Honorarium: None declared.

Received June 6, 2013; accepted September 4, 2013; previously published online October 23, 2013

\section{References}

1. Sapin R. The interference of insulin antibodies in insulin immunometric assays. Clin Chem Lab Med 2002;40: 705-8.
2. Sapin R. Insulin immunoassays: fast approaching 50 years of existence and still calling for standardization. Clin Chem 2007;53:810-2. 
3. Manley SE, Stratton IM, Clark PM, Luzio SD. Comparison of 11 human insulin assays: implications for clinical investigation and research. Clin Chem 2007;53:922-32.

4. Marcovina S, Bowsher RR, Miller WG, Staten M, Myers G, Caudill SP, et al. Standardization of insulin immunoassays: report of the American Diabetes Association Workgroup. Clin Chem 2007;53:711-6.

5. Rodriguez-Cabaleiro D, Van Uytfanghe K, Stove V, Fiers T, Thienpont LM. Pilot study for the standardization of insulin immunoassays with isotope dilution liquid chromatography/ tandem mass spectrometry. Clin Chem 2007;53:1462-9.

6. Hirsch IB. Insulin analogues. N Engl J Med 2005;352:174-83.

7. Thevis M, Thomas A, Delahaut P, Bosseloir A, Schanzer W. Qualitative determination of synthetic analogues of insulin in human plasma by immunoaffinity purification and liquid chromatography-tandem mass spectrometry for doping control purposes. Anal Chem 2005;77:3579-85.

8. Thevis M, Thomas A, Delahaut P, Bosseloir A, Schanzer W. Doping control analysis of intact rapid-acting insulin analogues in human urine by liquid chromatography-tandem mass spectrometry. Anal Chem 2006;78:1897-903.

9. Thevis M, Thomas A, Schanzer W. Insulin. Handb Exp Pharmacol 2010;195:209-26.

10. Thomas A, Schanzer W, Delahaut P, Thevis M. Sensitive and fast identification of urinary human, synthetic and animal insulin by means of nano-UPLC coupled with high-resolution/high-accuracy mass spectrometry. Drug Test Anal 2009;1:219-27.

11. Thomas A, Thevis M, Delahaut P, Bosseloir A, Schanzer W. Mass spectrometric identification of degradation products of insulin and its long-acting analogues in human urine for doping control purposes. Anal Chem 2007;79:2518-24.

12. Moriyama M, Hayashi N, Ohyabu C, Mukai M, Kawano S, Kumagai S. Performance evaluation and cross-reactivity from insulin analogs with the ARCHITECT insulin assay. Clin Chem 2006;52:1423-6.

13. Owen WE, Roberts WL. Cross-reactivity of three recombinant insulin analogs with five commercial insulin immunoassays. Clin Chem 2004;50:257-9.

14. Vieira JG, Tachibana TT, Ferrer CM, Reis AF. Cross-reactivity of new insulin analogs in insulin assays. Arq Bras Endocrinol Metabol 2007;51:504-5.

15. Krull I, Sahli R, Diem P, Stettler C. Variability in cross-reactivity of novel insulin analogues in immunometric insulin assays. Diabet Med 2009;26:1075-6.

16. Neal JM, Han W. Insulin immunoassays in the detection of insulin analogues in factitious hypoglycemia. Endocr Pract 2008;14:1006-10.

17. Agin A, Jeandidier N, Gasser F, Grucker D, Sapin R. Use of insulin immunoassays in clinical studies involving rapid-acting insulin analogues: $\mathrm{Bi}$-insulin IRMA preliminary assessment. Clin Chem Lab Med 2006;44:1379-82.

18. Cao Y, Smith WC, Bowsher RR. A sensitive chemiluminescent enzyme immunoassay for the bioanalysis of carboxyl-terminal B-chain analogues of human insulin. J Pharm Biomed Anal 2001;26:53-61.

19. Glenn C, Armston A. Cross-reactivity of 12 recombinant insulin preparations in the Beckman Unicel Dxl 800 insulin assay. Ann Clin Biochem 2010;47:264-6.
20. Kim S, Yun YM, Hur M, Moon HW, Kim JQ. The effects of anti-insulin antibodies and cross-reactivity with human recombinant insulin analogues in the E170 insulin immunometric assay. Korean J Lab Med 2011;31:22-9.

21. Sapin R, Le Galudec V, Gasser F, Pinget M, Grucker D. Elecsys insulin assay: free insulin determination and the absence of cross-reactivity with insulin lispro. Clin Chem 2001;47: 602-5.

22. Song D, Davidson J. Cross-reactivity of Actrapid and three insulin analogues in the Abbott IMx insulin immunoassay. Ann Clin Biochem 2007;44:197-8.

23. Armitage P, Berry G. Statistical methods in medical research, 3rd ed. Oxford: Blackwell, 1994.

24. Miller WG, Thienpont LM, Van Uytfanghe K, Clark PM, Lindstedt P, Nilsson G, et al. Toward standardization of insulin immunoassays. Clin Chem 2009;55:1011-8.

25. Kuerzel GU, Shukla U, Scholtz HE, Pretorius SG, Wessels DH, Venter C, et al. Biotransformation of insulin glargine after subcutaneous injection in healthy subjects. Curr Med Res Opin 2003;19:34-40.

26. Sommerfeld MR, Muller G, Tschank G, Seipke G, Habermann P, Kurrle R, et al. In vitro metabolic and mitogenic signaling of insulin glargine and its metabolites. PLoS One 2010;5:e9540.

27. Morovat A. Detection of Actrapid by insulin assays. Ann Clin Biochem 2007;44:315-6.

28. Marks A, Yip C, Wilson S. Characterization of two epitopes on insulin using monoclonal antibodies. Mol Immunol 1985;22:285-90.

29. Allauzen S, Joly S, Granier C, Molina F, Bouix O, Pau B, et al. Immunoanalysis of human insulin using monoclonal antibodies reveals antigenicity of evolutionarily conserved residues. Mol Immunol 1995;32:27-36.

30. Schroer JA, Bender T, Feldmann RJ, Kim KJ. Mapping epitopes on the insulin molecule using monoclonal antibodies. Eur J Immunol 1983;13:693-700.

31. Owens DR. Glargine and cancer: can we now suggest closure? Diabetes Care 2012;35:2426-8.

32. Pierre-Eugene C, Pagesy P, Nguyen TT, Neuille M, Tschank G, Tennagels N, et al. Effect of insulin analogues on insulin/IGF1 hybrid receptors: increased activation by glargine but not by its metabolites M1 and M2. PLoS One 2012;7:e41992.

33. Bolli GB, Hahn AD, Schmidt R, Eisenblaetter T, Dahmen R, Heise T, et al. Plasma exposure to insulin glargine and its metabolites M1 and M2 after subcutaneous injection of therapeutic and supratherapeutic doses of glargine in subjects with type 1 diabetes. Diabetes Care 2012;35:2626-30.

34. Lucidi P, Porcellati F, Rossetti P, Candeloro P, Andreoli AM, Cioli $P$, et al. Metabolism of insulin glargine after repeated daily subcutaneous injections in subjects with type 2 diabetes. Diabetes Care 2012;35:2647-9.

35. Miller JJ, Valdes R. Methods for calculating cross-reactivity in immunoassay. J Clin Immunoassay 1992;15:97-107.

36. Miller JJ, Valdes R, Jr. Approaches to minimizing interference by cross-reacting molecules in immunoassays. Clin Chem 1991;37:144-53.

37. Burge MR, McLeod J, Bowsher RR, Schade DS. Validity of Coat-A-Count insulin RIA kit for quantifying total and free humalog. Clin Chem 1996;42:777. 